\title{
XKR4 Gene Effects on Cerebellar Development Are Not Specific to ADHD
}

\author{
Devon Shook ${ }^{1 *}$, Rachel Brouwer ${ }^{2}$, Patrick de Zeeuw ${ }^{1}$, Bob Oranje $^{1}$ and Sarah Durston ${ }^{1 *}$ \\ ${ }^{1}$ NICHE Laboratory, Department of Psychiatry, Brain Center Rudolf Magnus, University Medical Center Utrecht, Utrecht, \\ Netherlands, ${ }^{2}$ Department of Psychiatry, Brain Center Rudolf Magnus, University Medical Center Utrecht, Utrecht, \\ Netherlands
}

\section{OPEN ACCESS}

Edited by:

Chris I. De Zeeuw,

Sophia Children's Hospital,

Netherlands

Reviewed by:

Paul Geoffrey Overton,

University of Sheffield,

United Kingdom

Erik B. Malarkey,

Vertex Pharmaceuticals,

United States

*Correspondence:

Devon Shook

d.a.shook@umcutrecht.nl;

dshook@hawaii.edu

Sarah Durston

s.durston@umcutrecht.nl

Received: 12 July 2017 Accepted: 28 November 2017 Published: 12 December 2017

Citation:

Shook $D$, Brouwer $R$, de Zeeuw $P$,

Oranje B and Durston S (2017)

XKR4 Gene Effects on Cerebellar

Development Are Not Specific

to $A D H D$.

Front. Cell. Neurosci. 11:396. doi: 10.3389/fncel.2017.00396
A single-nucleotide polymorphism (SNP) of the XKR4 gene has been linked to Attention-Deficit/Hyperactivity Disorder (ADHD). This gene is preferentially expressed in cerebellum, a brain structure implicated in this disorder. This study investigated the effects of this SNP on cerebellar development in children with and without ADHD. We collected 279 longitudinal T1-weighted structural images and DNA from 58 children with $\mathrm{ADHD}$ and 64 typically developing (TD) children matched for age, IQ, and gender. Groups were divided by the XKR4 rs2939678 SNP into A-allele carriers versus subjects homozygous for the G-allele. Cerebellar lobular volumes were segmented into 35 regions of interest using MAGeTBrain, an automated multi-atlas segmentation pipeline for anatomical MRI, and statistically analyzed using linear mixed models. We found decreased gray matter (GM) volumes in ADHD compared to TD children in bilateral lobules VIIIA, left VIIIB, right VIIB, and vermis VI. Furthermore, we found a linear age by gene interaction in left lobule VIIB where subjects homozygous for the G-allele showed a decrease in volume over time compared to A-allele carriers. We further found quadratic age $\times$ gene and age $\times$ diagnosis interactions in left lobule IV. Subjects homozygous for the G-allele (the genotype overtransmitted in ADHD) showed more suppressed, almost flat quadratic growth curves compared to A-allele carriers, similar to individuals with ADHD compared to controls. However, there was no interaction between genotype and diagnosis, suggesting that any effects of this SNP on cerebellar development are not specific to the disorder.

Keywords: XKR4, ADHD, cerebellum development, cerebellum, neurodevelopmental disorders

\section{INTRODUCTION}

Neuroimaging studies have implicated the cerebellum in Attention-Deficit/Hyperactivity Disorder (ADHD). However, findings have been inconsistent (Valera et al., 2007) and few studies have examined genetic risk-factors related to these changes. Two studies have suggested that there may be an association between a single-nucleotide polymorphism (SNP) in the XKR4-gene, which is expressed in the cerebellum, and ADHD (Neale et al., 2008; Lantieri et al., 2010). XKR4 codes for a XK-related protein in the XK-Kell blood group complex. While the function of this gene is not well characterized in the brain, $\mathrm{XK}$ is highly expressed in the Purkinje cells of the cerebellum in mouse and human tissue (Clapéron et al., 2007; Lee et al., 2007). It has been associated with addiction and substance abuse (Uhl et al., 2008), as well as cognitive deficits, including poor self-restraint, memory, executive function and neuropsychiatric symptoms in McLeod syndrome, a genetically transmitted disorder of the XK-Kell blood group complex (Danek et al., 2001; Jung et al., 2001; 
Danek and Walker, 2005; Hewer et al., 2007). Additionally, mutations upstream from the XKR4 gene have been shown to mediate response to antipsychotic medication (Lavedan et al., 2009; Fijal et al., 2012). An initial investigation from our lab of XKR4 genotype effects in ADHD showed an interaction with birth weight on decreased total cerebellar volume (De Zeeuw et al., 2012).

Although not all studies of cerebellum volume in ADHD have been consistent, several cerebellar regions have been implicated multiple times in the disorder. Early studies reported smaller total cerebellar volume in children and adolescents with ADHD compared to their typically developing (TD) peers (Castellanos et al., 1996), as well as smaller right cerebellum volume (Durston et al., 2004), and posterior vermis VIII-X volumes (Berquin et al., 1998; Mostofsky et al., 1998; Castellanos et al., 2001). More recent studies have replicated findings in posterior vermis (McAlonan et al., 2007; Yang et al., 2008) and suggested that there may be correlations with symptom severity (Bledsoe et al., 2011; Ivanov et al., 2014), as well as a normalizing effect of medication use (Bledsoe et al., 2009). In addition, reduced volume has been reported for left lobules IV-VI, VIII, IX, X and right lobules IV, VIII, IX (Seidman et al., 2011) and bilateral Crus I (Carmona et al., 2005; Montes et al., 2011). In adults with ADHD, a study using a whole brain ROI approach reported decreased gray matter (GM) in bilateral posterior cerebellum (Makris et al., 2015). Longitudinal studies have suggested that reductions in cerebellar volume in ADHD are stable over development (Castellanos et al., 2002; Mackie et al., 2007; Nakao et al., 2011).

In this study, we set out to investigate whether our previous findings of XKR4 gene effects on the cerebellum were regionally specific, stable over development and, particularly, related to ADHD diagnosis. We assessed the XKR4 rs2939678 SNP and measured regional cerebellar volumes in a longitudinal sample and ran mixed model regression analyses to investigate the effect of the SNP associated with ADHD on cerebellar development. We hypothesized that the associated polymorphism of XKR4 and diagnosis would both be associated with reduced volume, specifically in previously implicated areas, that changes would be stable over development and that there would be an interaction between genotype and diagnosis, where gene effects were greatest for those individuals affected by the disorder.

\section{MATERIALS AND METHODS}

The Medical Ethical Review Board of the University Medical Center Utrecht approved the study and its procedures.

\section{Participants}

One hundred and twenty-two children (64 TD and 58 children with $\mathrm{ADHD}$ ) participated in this study from a larger ongoing longitudinal cohort for whom DAT1 and DRD4 had previously been determined (Durston et al., 2005). Groups were matched for age, gender, and IQ (Table 1). Written consent was obtained from the parents with full knowledge of the purpose and procedure of the study and children provided written or verbal assent. To confirm inclusion criteria, the DISC-IV parent version
(Shaffer et al., 2000) was administered to confirm clinical diagnosis of ADHD or rule out psychiatric morbidity in control participants. In controls, exclusion criteria included history of psychiatric illness in a first-degree relative or any major physical or neurological disorder. In both groups, additional exclusion criteria included any major physical or neurological disorder including dyslexia. Additionally, parents completed the Child Behavior Checklist (CBCL; Verhulst et al., 1996) for a dimensional measure of behavioral symptoms. A four subset Dutch short version of the WISC-R or WISC-III (Wechsler, 2005) was used to assess IQ. At baseline scan, information on medication use was available for 46 of the participants with ADHD, of which 38 reported a history of taking psychostimulants (methylphenidate) and one taking amphetamines (dexamphetamine; Table 1).

There were a total of 279 scans available from these 122 children (Figure 1). Eighty-one children contributed at least a single follow-up scans (TD: 48, ADHD: 33), 51 had a third scan (TD: 37, ADHD: 14), and 25 had a fourth scan (TD: 21, ADHD: 4).

\section{Data Acquisition and Processing}

A T1-weighted 3D fast field echo scan of the whole head was acquired with 130-150 1.5-mm contiguous coronal slices (Philips Intera; 107 scans) or 160-180 1.2-mm contiguous coronal slices (Philips Achieva; 172 scans) with echo time (TE) $4.6 \mathrm{~ms}$; repetition time (TR) $30 \mathrm{~ms}$; flip angle $30^{\circ}$; field of view (FOV) $256 \mathrm{~mm}$; in-plane voxel size $1 \mathrm{~mm} \times 1 \mathrm{~mm}$.

Scans were processed using MAGeT-Brain ${ }^{1}$, an automated multi-atlas segmentation pipeline for anatomical MRI. Technical details of the segmentation can be found elsewhere (Park et al., 2014). Briefly, MAGeT-Brain uses multiple manually labeled high resolution atlases to generate candidate labels for each voxel. Labels are generated by non-linear registration of randomly selected templates to the anatomical atlases, which are then propagated to the target image and candidate labels are chosen via majority vote. For the current project, the cerebellum was segmented into 35 regions of interest (ROIs) including bilateral and vermis III-X (including VIIB and VIIIA/B) as well as bilateral crus I/II and vermis I, VIIA, and corpus medullare.

\section{DNA Collection and Genotyping}

DNA was collected using buccal swabs as described previously (Durston et al., 2005; De Zeeuw et al., 2012). We selected a SNP in the XKR4-gene that showed nominal significance in two independent association studies (Neale et al., 2008; Lantieri et al., 2010): rs2939678. It was genotyped using Applied Biosystems' TaqMan SNP assays on ABI Prism 7900 HT realtime thermocyclers. Call rate was $>95 \%$, and the SNP did not deviate strongly from Hardy-Weinberg (HW) equilibrium in controls. The XKR4 SNP was recoded to homozygous GG-allele and A-allele carriers (AA and GA) as the number of subjects with homozygous AA-allele carriers was low (one TD, three ADHD subjects). Final groups demographics for baseline are shown in Table 1.

\footnotetext{
${ }^{1}$ https://github.com/CobraLab/MAGeTbrain
} 
TABLE 1 | Demographic and clinical characteristics [mean (SD)] at baseline.

\begin{tabular}{|c|c|c|c|c|}
\hline Baseline & TD-GG & TD-A carrier & ADHD-GG & ADHD-A carrier \\
\hline Gender (M/F) & $42 / 8$ & $13 / 1$ & $32 / 5$ & $20 / 1$ \\
\hline Age (year) & $10.1(2.0)$ & $10.3(1.5)$ & $10.7(1.9)$ & $10.4(2.5)$ \\
\hline $\mathrm{IQ}$ & $105.2(14.4)$ & $107.9(17.0)$ & $104.2(16.5)$ & $102.1(17.8)$ \\
\hline \multicolumn{5}{|l|}{ DISC (N) } \\
\hline inattentive & & & 6 & 5 \\
\hline hyperactive/impulsive & & & 8 & 3 \\
\hline combined & & & 23 & 13 \\
\hline ODD & & & 13 & 9 \\
\hline CBCL attention problems & $2.8(2.3)$ & $2.8(2.4)$ & $9.1(2.6)$ & $9.5(3.5)$ \\
\hline Medication users & & & 26 & 12 \\
\hline
\end{tabular}

GG, homozygous G-allele; TD, typically developing; ADHD, Attention-Deficit/Hyperactivity Disorder; CBCL, Child Behavior Checklist.

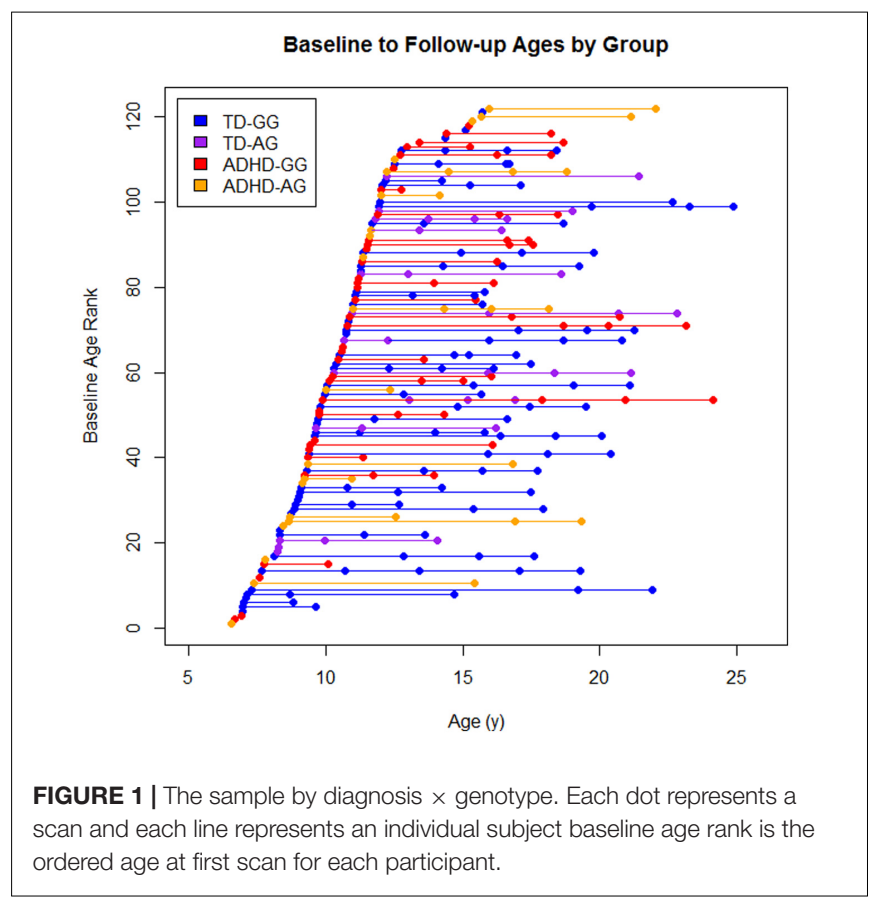

\section{Statistical Analysis}

To investigate the relationship between age and volume we used a linear mixed model procedure accounting for uneven interscan intervals, missing data and within subject dependence (Fox, 2002). Analyses were performed using the lme4 package in $\mathrm{R}$ (Bates et al., 2015). Each dependent measure of the ith family, jth individual, and kth time-point was modeled as described by Raznahan et al. (2011). Several models including cubic, quadratic and linear age, as well as genotype and diagnosis terms were fit. Intercept, age, diagnosis, and genotype effects were fixed while within person dependence was modeled as a random effect.

The best fit model for each lobule was determined in two steps. First, cubic, quadratic and linear age effects were fit for each lobule using a stepwise approach, where we stepped down to the quadratic model if the cubic model was not significant at $p<0.05$, etc. Second, the result was fit to three models: (1) Full interaction between diagnosis, genotype and age, (2) a simpler model with two-way interactions terms and, (3) the simplest model including only main effects. The three models were then compared using the Akaike Information Criterion (AIC) to find the model fit that explained the most variance while reducing the number of parameters. In each model, gender and slice thickness were entered as covariates. The interrelated nature of the measures means that traditional methods for correcting for multiple comparisons, such as a Bonferroni correction, are overly stringent for this type of study and there is debate in the literature on how to deal with this issue. In this paper, we chose to not apply any correction, given that our main hypothesis was not confirmed even without correction for multiple comparisons. Lastly, we tested for differences in demographic indices using $\chi^{2}$ and 4-group ANOVA where appropriate.

\section{RESULTS}

At baseline, groups were matched for age $(p=0.55)$, IQ $(p=0.76)$, gender $\left(\chi^{2}=2.13, p=0.54\right)$ and slice-thickness $\left(\chi^{2}=1.53, p=0.68\right)$.

There was a main effect of diagnosis in five areas (Figure 2 and Table 2), where children with ADHD showed decreased volume compared to TD controls: in bilateral lobules VIIIA (left: $p=0.002$; right: $p=0.026)$, left VIIIB $(p=0.013)$, right VIIB $(p=0.018)$, and vermis VI (0.024). There were no main effects of genotype. We did find an interaction between genotype and age in left lobule VIIB ( $p=0.003$; Table 2 and Figure 3 ) and one between genotype and quadratic growth in left lobule IV $(p=0.044$; Table 2 and Figure 3). In this last area, there was also an interaction between diagnostic group and quadratic growth ( $p=0.048$; Table 2 and Figure 3). There were no interactions between genotype and diagnosis. Nor were there any three-way interactions.

\section{DISCUSSION}

The current study set out to investigate whether XKR4 gene effects on cerebellar GM structure were regionally specific, were stable over development and were related to ADHD. Our primary hypothesis was that the XKR4 polymorphism previously 


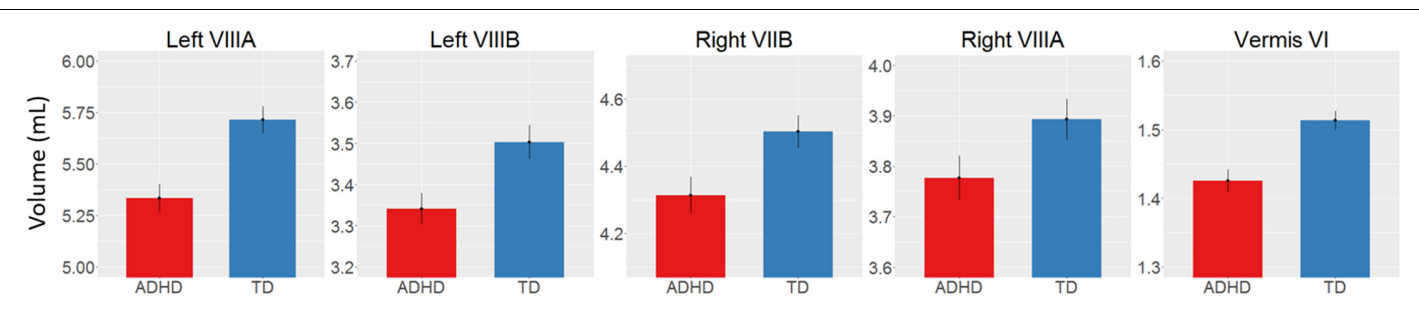

FIGURE 2 | Decreased volume in children with ADHD compared to typically developing children. Y-scale in $\mathrm{mL}$.

TABLE 2 | Best fit regression model for each volume in $\mathrm{mL}$.

\begin{tabular}{|c|c|c|c|c|c|c|c|c|c|}
\hline Lobule & Model & Intercept & Diagnosis & Gene & $D \times G$ & $D \times A$ & $\mathbf{G} \times \mathbf{A}$ & $D \times A^{2}$ & $G \times A^{2}$ \\
\hline Left VIIIA & Linear & $4.823(0.476)$ & $0.42(0.133)^{* *}$ & $-0.101(0.147)$ & & & & & \\
\hline Vermis VI & Linear & $1.475(0.08)$ & $0.073(0.032)^{*}$ & $-0.002(0.035)$ & & & & & \\
\hline Right VIIB & Linear & $3.521(0.377)$ & $0.236(0.099)^{*}$ & $-0.03(0.109)$ & & & & & \\
\hline Right VIIIA & Linear & $3.305(0.304)$ & $0.188(0.083)^{*}$ & $-0.002(0.092)$ & & & & & \\
\hline Left VIIB & Linear & $3.27(0.368)$ & $0.216(0.16)$ & $-0.056(0.131)$ & $-0.049(0.189)$ & $0(0.012)$ & $-0.039(0.013)^{* *}$ & & \\
\hline Left VIIIB & Quadratic & $1.97(0.277)$ & $0.198(0.078)^{*}$ & $0.078(0.087)$ & & & & & \\
\hline Left IV & Quadratic & $2.503(0.234)$ & $0.104(0.113)$ & $-0.145(0.094)$ & $0.012(0.128)$ & 0.009 (0.009) & -0.034 (0.009) & $-0.003(0.002)^{*}$ & $0.004(0.002)^{*}$ \\
\hline
\end{tabular}

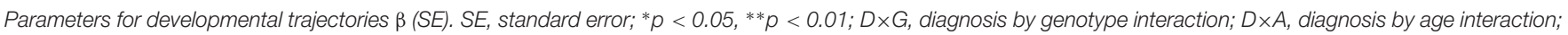
$G \times A$, genotype by age interaction.

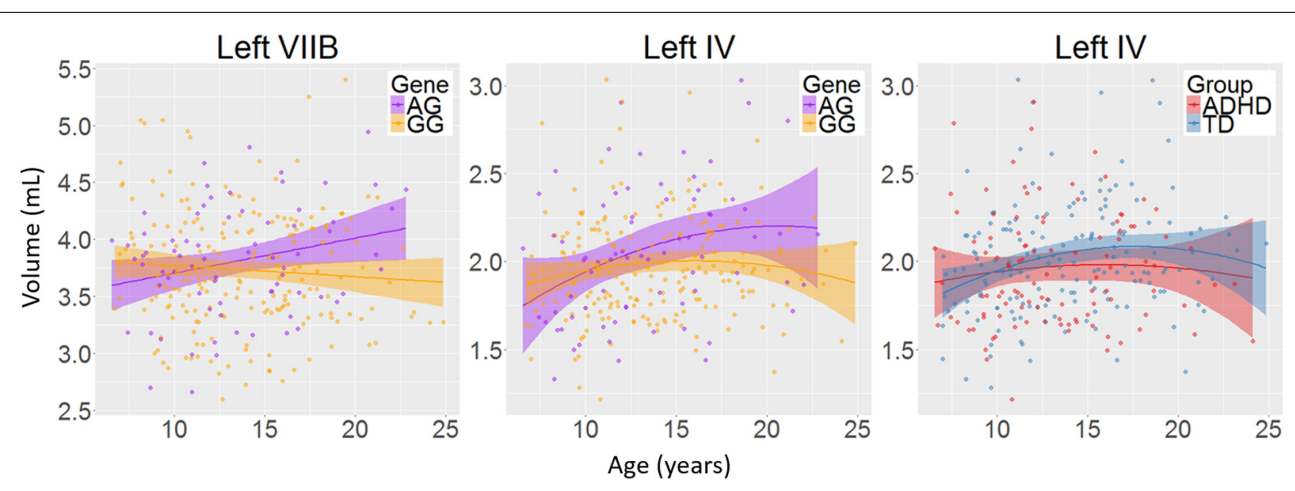

FIGURE 3 | The interactions between age and genotype for left lobule VIIB and IV volumes and between age and diagnosis for left lobule IV volume. Age in years; volume in $\mathrm{mL}$; shade represents $95 \%$ confidence intervals.

associated with ADHD would interact with diagnosis to for structural differences found in ADHD. This was not confirmed. However, we did find decreases in regional cerebellar GM associated with ADHD, as well as protracted developmental trajectories for children homozygous for the G-allele in left lobules VIIB and IV. This latter finding was similar to the current finding in children with ADHD. Overall, our findings suggest that any effects of XKR4 genotype on cerebellar structure are not specific to $\mathrm{ADHD}$, and do not mirror changes associated with the disorder.

We found decreases in regional GM volume in $\mathrm{ADHD}$, including in bilateral lobule VIII, right VIIB, and vermis VI. Lobule VIII is most notably associated with motor and somatosensory processing (Bushara et al., 2001; Grodd et al., 2001; Stoodley and Schmahmann, 2009) and the current result may relate to abnormal motor activity seen in ADHD (Hove et al., 2015). Lobule VII has been associated with language processing, working memory and executive function (Stoodley and Schmahmann, 2009; Buckner et al., 2011) and changes in this lobule may therefore be related to the difficulties in these areas that some individuals with ADHD experience (Doyle et al., 2005; Jonsdottir et al., 2006). One earlier study also reported decreases in volume in vermis VI in ADHD and many studies have reported decreased volumes in posterior inferior vermis VIII-X (Berquin et al., 1998; Mostofsky et al., 1998; Castellanos et al., 2001; Bussing et al., 2002; Goetz et al., 2014). However, these studies have In addition to regional changes in GM volumes in $\mathrm{ADHD}$, we found a genotype by age interaction in left lobule VIIB with subjects homozygous for the G-allele showed a downward growth slope over development and A-allele carriers showed an typically only included children, had small sample sizes or only examined relatively large unsegmented sections of the vermis. upward slope into early adulthood. Furthermore, we found an interaction of age with both diagnostic group and genotype 
in left lobule IV. Here, the ADHD group showed a more suppressed, almost flat quadratic growth curve compared to TD controls with a peak in late adolescence. Subjects homozygous for the G-allele (the genotype relatively overtransmitted in ADHD) showed a similar trajectory compared to A-carriers. Lobule IV has been associated with motor activity (Stoodley et al., 2012) and anatomical cerebral-cerebellar motor connections (Schmahmann and Pandya, 1997). Differences in this region may be related for the hyperactive motor behavior in ADHD (Pitcher et al., 2003) and motor tics in XKR4 related disorders (Danek et al., 2001).

There are some limitations to our current study. We note that the sample size of the A-allele carrier groups at baseline was relatively small $(N=35$ : $\mathrm{TD}=14, \mathrm{ADHD}=21)$. Furthermore, the sample size at follow-up was also limited due to attrition. This may have led to null findings for some of the higher order interactions. We also note that multiple comparison correction that was not applied in the current study and therefore suggest a need for future replication. Lastly, we suggest future studies examine whether XKR4 expression may influence ADHD development in the cortex.

In summary, we found decreased GM volume in several posterior lobules of the cerebellum associated with ADHD, similar to earlier studies. We found no evidence of main effects of XKR4 genotype on cerebellar volumes, and only limited effects on regional developmental trajectories. Furthermore, there were no interactions between genotype and diagnosis. In all, these findings suggest that any changes in cerebellum associated with ADHD are not due to effects of XKR4 genotype on cerebellar structure.

\section{REFERENCES}

Bates, D., Maechler, M., Bolker, B., and Walker, S. (2015). Fitting linear mixedeffects models using lme4. J. Stat. Softw. 67, 1-48. doi: 10.18637/jss.v067.i01

Berquin, P. C., Giedd, J. N., Jacobsen, L. K., Hamburger, S. D., Krain, A. L., Rapoport, J. L., et al. (1998). Cerebellum in attention-deficit hyperactivity disorder: a morphometric MRI study. Neurology 50, 1087-1093. doi: 10.1212/ WNL.50.4.1087

Bledsoe, J., Semrud-Clikeman, M., and Pliszka, S. R. (2009). A magnetic resonance imaging study of the cerebellar vermis in chronically treated and treatment-naïve children with attention-deficit/hyperactivity disorder combined type. Biol. Psychiatry 65, 620-624. doi: 10.1016/j.biopsych.2008. 11.030

Bledsoe, J. C., Semrud-Clikeman, M., and Pliszka, S. R. (2011). Neuroanatomical and neuropsychological correlates of the cerebellum in children with attentiondeficit/hyperactivity disorder-combined type. J. Am. Acad. Child Adolesc. Psychiatry 50, 593-601. doi: 10.1016/j.jaac.2011.02.014

Buckner, R. L., Krienen, F. M., Castellanos, A., Diaz, J. C., and Yeo, B. T. T. (2011). The organization of the human cerebellum estimated by intrinsic functional connectivity. J. Neurophysiol. 106, 2322-2345. doi: 10.1152/jn.003 39.2011

Bushara, K. O., Wheat, J. M., Khan, A., Mock, B. J., Turski, P. A., Sorenson, J., et al. (2001). Multiple tactile maps in the human cerebellum. Neuroreport 12, 2483-2486. doi: 10.1097/00001756-200108080-200108039

Bussing, R., Grudnik, J., Mason, D., Wasiak, M., and Leonard, C. (2002). ADHD and conduct disorder: an MRI study in a community sample. World J. Biol. Psychiatry 3, 216-220. doi: 10.3109/15622970209150624

Carmona, S., Vilarroya, O., Bielsa, A., Trèmols, V., Soliva, J. C., Rovira, M., et al. (2005). Global and regional gray matter reductions in ADHD: a voxel-based morphometric study. Neurosci. Lett. 389, 88-93. doi: 10.1016/j.neulet.2005. 07.020

\section{AUTHOR CONTRIBUTIONS}

All authors of this manuscript contributed substantially to the scientific process and the writing of the paper. Their contribution included the conception and design of the project, the running of the study, as well as the analysis and interpretation of data. In addition, all authors substantially contributed to either drafting or critically revising the manuscript for important intellectual content and state that they are entirely responsible for the scientific content of this paper.

\section{FUNDING}

This work was supported by VIDI grant 91.776.384 and VICI grant 453-10-005 from Netherlands Organization for Scientific Research (NWO) to SD.

\section{ACKNOWLEDGMENTS}

The authors thank all children, parents, and teachers who participated in this study. They further wish to thank Juliette Weusten, Lizanne Schweren, Fenny Zwart, Sanne Veerhoek, Janna van Belle, and Nathalie Vessaz for their assistance with subject recruitment and acquisition of MRI scans throughout the running time of this study, PdZ for his input and Gabriel Devenyi for their help with data-analysis.

Castellanos, F., Giedd, J. N., Berquin, P. C., Walter, J. M., Sharp, W., Tran, T., et al. (2001). Quantitative brain magnetic resonance imaging in girls with attentiondeficit/hyperactivity disorder. Arch. Gen. Psychiatry 58, 289-295. doi: 10.1001/ archpsyc.58.3.289

Castellanos, F. X., Giedd, J. N., Marsh, W. L., Hamburger, S. D., Vaituzis, A. C., Dickstein, D. P., et al. (1996). Quantitative brain magnetic resonance imaging in attention-deficit hyperactivity disorder. Arch. Gen. Psychiatry 53, 607-616. doi: 10.1001/archpsyc.1996.01830070053009

Castellanos, F. X., Lee, P. P., Sharp, W., Jeffries, N. O., Greenstein, D. K., Clasen, L. S., et al. (2002). Developmental trajectories of brain volume abnormalities in children and adolescents with attention-deficit/hyperactivity disorder. J. Am. Med. Assoc. 288, 1740-1748. doi: 10.1001/jama.288. 14.1740

Clapéron, A., Hattab, C., Armand, V., Trottier, S., Bertrand, O., and Ouimet, T. (2007). The Kell and XK proteins of the Kell blood group are not co-expressed in the central nervous system. Brain Res. 1147, 12-24. doi: 10.1016/j.brainres. 2007.01.106

Danek, A., Rubio, J. P., Rampoldi, L., Ho, M., Dobson-Stone, C., Tison, F., et al. (2001). McLeod neuroacanthocytosis: genotype and phenotype. Ann. Neurol. 50, 755-764. doi: 10.1002/ana.10035

Danek, A., and Walker, R. H. (2005). Neuroacanthocytosis. Curr. Opin. Neurol. 18, 386-392. doi: 10.1097/01.wco.0000173464.01888.e9

De Zeeuw, P., van Belle, J., van Dijk, S., Weusten, J., Koeleman, B., Janson, E., et al. (2012). Imaging gene and environmental effects on cerebellum in attentiondeficit/hyperactivity disorder and typical development. Neuroimage Clin. 2, 103-110. doi: 10.1016/j.nicl.2012.11.010

Doyle, A. E., Faraone, S. V., Seidman, L. J., Willcutt, E. G., Nigg, J. T., Waldman, I. D., et al. (2005). Are endophenotypes based on measures of executive functions useful for molecular genetic studies of ADHD? J. Child Psychol. Psychiatry Allied Discip. 46, 774-803. doi: 10.1111/j.1469-7610.2005. 01476.x 
Durston, S., Fossella, J. A., Casey, B. J., Hulshoff Pol, H. E., Galvan, A., Schnack, H. G., et al. (2005). Differential effects of DRD4 and DAT1 genotype on frontostriatal gray matter volumes in a sample of subjects with attention deficit hyperactivity disorder, their unaffected siblings, and controls. Mol. Psychiatry 10, 678-685. doi: 10.1038/sj.mp.4001649

Durston, S., Hulshoff Pol, H. E., Schnack, H. G., Buitelaar, J. K., Steenhuis, M. P., Minderaa, R. B., et al. (2004). Magnetic resonance imaging of boys with attention-deficit/hyperactivity disorder and their unaffected siblings. J. Am. Acad. Child Adolesc. Psychiatry 43, 332-340. doi: 10.1097/01.chi.0000107729. $75340 . \mathrm{f3}$

Fijal, B. A., Stauffer, V. L., Kinon, B. J., Conley, R. R., Hoffmann, V. P., Witte, M. M., et al. (2012). Analysis of gene variants previously associated with iloperidone response in patients with schizophrenia who are treated with risperidone. J. Clin. Psychiatry 73, 367-371. doi: 10.4088/JCP.10m06507

Fox, J. (2002). Linear Mixed Models-Appendix to An R and S-Plus Companion to Applied Regression. Thousand Oaks, CA: Sage Publications.

Goetz, M., Vesela, M., and Ptacek, R. (2014). Notes on the role of the cerebellum in ADHD. Austin J. Psychiatry Behav. Sci. 1:6.

Grodd, W., Hulsmann, E., Lotze, M., Wildgruber, D., and Erb, M. (2001). Sensorimotor mapping of the human cerebellum: fMRI evidence of somatotopic organization. Hum. Brain Mapp. 13, 55-73. doi: 10.1002/hbm.1025

Hewer, E., Danek, A., Schoser, B. G., Miranda, M., Reichard, R., Castiglioni, C., et al. (2007). McLeod myopathy revisited: more neurogenic and less benign. Brain 130, 3285-3296. doi: 10.1093/brain/awm269

Hove, M. J., Zeffiro, T. A., Biederman, J., Li, Z., Schmahmann, J., and Valera, E. M. (2015). Postural sway and regional cerebellar volume in adults with attentiondeficit/hyperactivity disorder. Neuroimage Clin. 8, 422-428. doi: 10.1016/j.nicl. 2015.05.005

Ivanov, I., Murrough, J. W., Bansal, R., Hao, X., and Peterson, B. S. (2014). Cerebellar morphology and the effects of stimulant medications in youths with attention deficit-hyperactivity disorder. Neuropsychopharmacology 39, 718-726. doi: 10.1038/npp.2013.257

Jonsdottir, S., Bouma, A., Sergeant, J. A., and Scherder, E. J. (2006). Relationships between neuropsychological measures of executive function and behavioral measures of ADHD symptoms and comorbid behavior. Arch. Clin. Neuropsychol. 21, 383-394. doi: 10.1016/j.acn.2006.05.003

Jung, H. H., Hergersberg, M., Kneifel, S., Alkadhi, H., Schiess, R., WeigellWeber, M., et al. (2001). McLeod syndrome: a novel mutation, predominant psychiatric manifestations, and distinct striatal imaging findings. Ann. Neurol. 49, 384-392. doi: 10.1002/ana.76

Lantieri, F., Glessner, J. T., Hakonarson, H., Elia, J., and Devoto, M. (2010). Analysis of GWAS top hits in ADHD suggests association to two polymorphisms located in genes expressed in the cerebellum. Am. J. Med. Genet. B Neuropsychiatr. Genet. 153, 1127-1133. doi: 10.1002/ajmg.b.31110

Lavedan, C., Licamele, L., Volpi, S., Hamilton, J., Heaton, C., Mack, K., et al. (2009). Association of the NPAS3 gene and five other loci with response to the antipsychotic iloperidone identified in a whole genome association study. Mol. Psychiatry 14, 804-819. doi: 10.1038/mp.2008.56

Lee, S., Sha, Q., Wu, X., Calenda, G., and Peng, J. (2007). Expression profiles of mouse Kell, XK, and XPLAC mRNA. J. Histochem. Cytochem. 55, 365-374. doi: 10.1369/jhc.6A7126.2006

Mackie, S., Shaw, P., Lenroot, R., Pierson, R., Greenstein, D. K., Nugent, T. F., et al. (2007). Cerebellar development and clinical outcome in attention deficit hyperactivity disorder. Am. J. Psychiatry 164, 647-655. doi: 10.1176/appi.ajp. 164.4.647

Makris, N., Liang, L., Biederman, J., Valera, E. M., Brown, A. B., Petty, C., et al. (2015). Toward defining the neural substrates of ADHD: a controlled structural MRI study in medication-naïve adults. J. Atten. Disord. 19, 944-953. doi: 10. $1177 / 1087054713506041$

McAlonan, G. M., Cheung, V., Cheung, C., Chua, S. E., Murphy, D. G. M., Suckling, J., et al. (2007). Mapping brain structure in attention deficithyperactivity disorder: a voxel-based MRI study of regional grey and white matter volume. Psychiatry Res. 154, 171-180. doi: 10.1016/j.pscychresns.2006. 09.006

Montes, L. G. A., Ricardo-Garcell, J., De la Torre, L. B., Alcántara, H. P., García, R. B. M., Acosta, D. A., et al. (2011). Cerebellar gray matter density in females with ADHD combined type: a cross-sectional voxel-based morphometry study. J. Atten. Disord. 15, 368-381. doi: 10.1177/1087054710366421
Mostofsky, S. H., Reiss, A. L., Lockhart, P., and Denckla, M. B. (1998). Evaluation of cerebellar size in attention-deficit hyperactivity disorder. J. Child Neurol. 13, 434-439. doi: 10.1177/088307389801300904

Nakao, T., Radua, J., Rubia, K., and Mataix-Cols, D. (2011). Gray matter volume abnormalities in ADHD: voxel-based meta-analysis exploring the effects of age and stimulant medication. Am. J. Psychiatry 168, 1154-1163. doi: 10.1176/appi. ajp.2011.11020281

Neale, B. M., Lasky-Su, J., Anney, R., Franke, B., Zhou, K., Maller, J. B., et al. (2008). Genome-wide association scan of attention deficit hyperactivity disorder. Am. J. Med. Genet. B Neuropsychiatr. Genet. 147B, 1337-1344. doi: 10.1002/ajmg.b. 30866

Park, M. T. M., Pipitone, J., Baer, L. H., Winterburn, J. L., Shah, Y., Chavez, S., et al. (2014). Derivation of high-resolution MRI atlases of the human cerebellum at $3 \mathrm{~T}$ and segmentation using multiple automatically generated templates. Neuroimage 95, 217-231. doi: 10.1016/j.neuroimage.2014. 03.037

Pitcher, T. M., Piek, J. P., and Hay, D. A. (2003). Fine and gross motor ability in males with ADHD. Dev. Med. Child Neurol. 45, 525-535. doi: 10.1111/j.14698749.2003.tb00952.x

Raznahan, A., Shaw, P., Lalonde, F., Stockman, M., Wallace, G. L., Greenstein, D., et al. (2011). How does your cortex grow? J. Neurosci. 31, 7174-7177. doi: 10.1523/JNEUROSCI.0054-11.2011

Schmahmann, J. D., and Pandya, D. N. (1997). The cerebrocerebellar system. Int. Rev. Neurobiol. 41, 31-60. doi: 10.1016/s0074-7742(08)60346-3

Seidman, L. J., Biederman, J., Liang, L., Valera, E. M., Monuteaux, M. C., Brown, A., et al. (2011). Gray matter alterations in adults with attentiondeficit/hyperactivity disorder identified by voxel based morphometry. Biol. Psychiatry 69, 857-866. doi: 10.1016/j.biopsych.2010.09.053

Shaffer, D., Fisher, P., Lucas, C. P., Dulcan, M. K., and Schwab-Stone, M. E. (2000). NIMH diagnostic interview schedule for children version IV (NIMH DISC-IV): description, differences from previous versions, and reliability of some common diagnoses. J. Am. Acad. Child Adolesc. Psychiatry 39, 28-38. doi: 10.1097/00004583-200001000-00014

Stoodley, C. J., and Schmahmann, J. D. (2009). Functional topography in the human cerebellum: a meta-analysis of neuroimaging studies. Neuroimage 44, 489-501. doi: 10.1016/j.neuroimage.2008.08.039

Stoodley, C. J., Valera, E. M., and Schmahmann, J. D. (2012). Functional topography of the cerebellum for motor and cognitive tasks: an fMRI study. Neuroimage 59, 1560-1570. doi: 10.1016/j.neuroimage.2011. 08.065

Uhl, G. R., Drgon, T., Johnson, C., Fatusin, O. O., Liu, Q. R., Contoreggi, C., et al. (2008). "Higher order" addiction molecular genetics: convergent data from genome-wide association in humans and mice. Biochem. Pharmacol. 75, 98-111. doi: 10.1016/j.bcp.2007.06.042

Valera, E. M., Faraone, S. V, Murray, K. E., and Seidman, L. J. (2007). Meta-analysis of structural imaging findings in attention-deficit/hyperactivity disorder. Biol. Psychiatry 61, 1361-1369. doi: 10.1016/j.biopsych.2006.06.011

Verhulst, F., Van Der Ende, J., and Koot, H. (1996). Handleiding voor de CBCL/4-18 (Manual for the CBCL/4-18). Rotterdam: Erasmus Academic Medical Centre.

Wechsler, D. (2005). Wechsler Intelligence Scale for Children - Derde Editie NL. Handleiding en Verantwoording (Wechsler Intelligence Scale for Children, Dutch Version, Manual, 3rd Edn. London: Harcourt Assessment.

Yang, P., Wang, P.-N., Chuang, K.-H., Jong, Y.-J., Chao, T.-C., and Wu, M.-T. (2008). Absence of gender effect on children with attention-deficit/hyperactivity disorder as assessed by optimized voxel-based morphometry. Psychiatry Res. 164, 245-253. doi: 10.1016/j.pscychresns.2007.12.013

Conflict of Interest Statement: The authors declare that the research was conducted in the absence of any commercial or financial relationships that could be construed as a potential conflict of interest.

Copyright $\odot 2017$ Shook, Brouwer, de Zeeuw, Oranje and Durston. This is an openaccess article distributed under the terms of the Creative Commons Attribution License (CC BY). The use, distribution or reproduction in other forums is permitted, provided the original author(s) or licensor are credited and that the original publication in this journal is cited, in accordance with accepted academic practice. No use, distribution or reproduction is permitted which does not comply with these terms. 